\title{
Demand for Natural Disaster Insurance
}

\author{
by Yasushi Morimiya *
}

\section{Introduction}

Modern society faces such perils as earthquake, flood, windstorm, heavy rain and snow so severe that the individual by himself cannot expect to cope with them. Natural disasters basically have two facets. First, they can occur in specific areas with certain frequency, making adverse selection possible. Secondly, such perils often amplify the severity of damage through man-made hazards by regional development in our society.

Many may feel loss prevention (e.g. flood control, building regulation codes) and loss financing (e.g. disaster relief loans) for natural disasters should be provided by government and/or municipalities. We must not, however, fail to recognize the necessity for individual efforts, though man is most susceptible to the destructive power of nature. Traditionally, we have created new types of insurance coverages according to our perceived need to protect our possessions.

\section{Purpose}

The purpose of this paper is to consider the structure of our demand for natural disaster insurance in a social framework and to review the brief history of Japanese adaptation to natural disasters.

My premise is that insurers will respond to estimated aggregate demand and provide insurance coverages. And government should play some role to provide coverages for natural disaster, if private efforts would not be enough to meet demands.

It may not miss the mark to say that the sum of individual demand equals the aggregate, for aggregate demand implies a potential group of insureds for pooling in the insurance sense.

This is the beginning of recognition of the mechanism of individual demand.

\footnotetext{
* Professor of Insurance, School of Commerce, Meiji University.
} 


\section{Framework for recognizing demand for natural disaster insurance}

There are at least three factors to approach the demand for natural disaster insurance. First, we need to understand who may suffer such disasters from perils compounded by natural and man-made hazards. Secondly, what values are exposed to natural disasters? This implies the vulnerability of life and insurable property. Thirdly, what factors stimulate potential insureds to seek natural disaster insurance? In order to discuss these factors, it might be useful to introduce a concept : cognizant entity.

Figure 1 represents a framework for recognizing the process of demand for disaster insurance coverages.

Figure 1

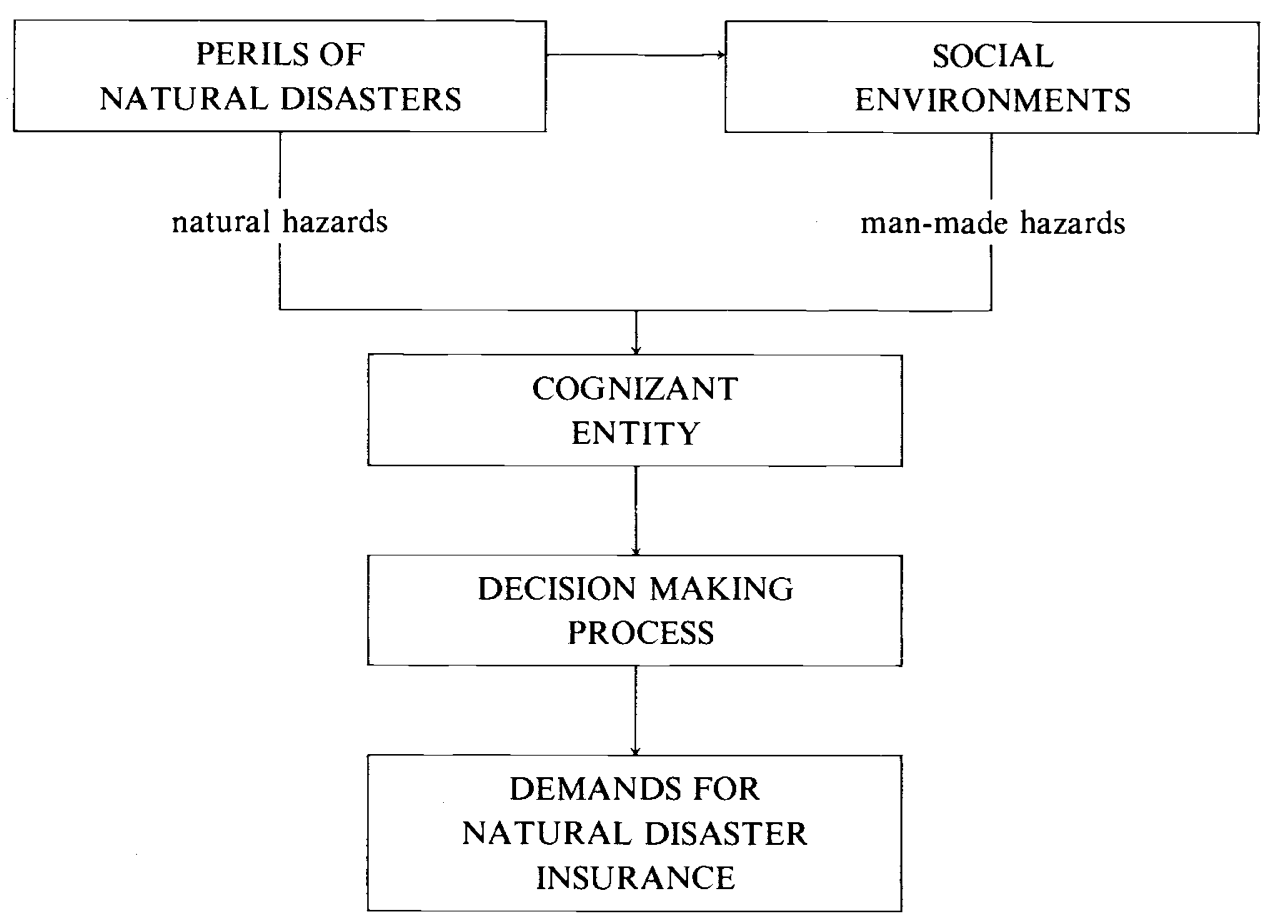

\subsection{Cognizant entity}

Cognizant entity is a newly coined concept ${ }^{1}$. An " entity " implies existence, separate and self-contained and includes any individual or a group of individual entities. The latter

\footnotetext{
${ }^{1}$ Morimiya, Yasushi, "Insurance and Social Environments", The Bulletin of the Faculty of Commerce, Meiji University, Vol. 55, No. 8, 1973 (Japanese).
} 
may be a family or corporation. "Cognizant" refers to being capable of perceiving external environments. A cognizant entity here can judge the financial impact of disasters, purposively seek out the best alternative solution, if any, of financing techniques and utilize them.

This process is influenced by internalized value premises learnt from the past through social, religious experiences. And these internalized value premises and the past individual experience(s) of natural disasters will define the attitude of a cognizant entity toward disaster insurance coverage.

The following discussion will be centered on cognizant entity derived from the general public level.

\subsection{Perils of natural disasters and cognizant entity}

Our society is a mosaic of both natural and man-made hazards, which increase the impacts of damages when meshed with perils such as earthquake, volcanic activity, landslide, avalanche, typhoon, snowslide, tidal wave, drought and so forth. If natural disasters are extremely huge, cognizant entities are generally obliged to accept their influences, as the destructive power of nature often prevails over human effort. They tend to feel mutually that all have equally suffered.

Natural disasters, however, are not only of a low-probability and severe-loss nature. Man-made hazards accelerated by urbanization have created new flood-prone areas where flood damages tend to repeat with heavy rainfalls and typhoons in specific regions. Though we know the interrelationship between nature and man-made hazards, we have not yet succeeded in controlling natural disasters.

Furthermore, the cognizant entity at the general public level often fails to recognize the influence of natural disasters in terms of the same importance, for particular perils such as earthquake are inclined to occur in specific disaster-prone areas and different cognizant entities' holdings differ by regions.

\subsection{What values are exposed to natural disasters}

There are various opinions on how cognizant entities weigh values, and several approaches to the value system. Property insurable may serve as our example. The volume of properties possessed depends upon the income level of cognizant entities and corresponds to stages of economic development. The more income, the more goods owned, up to a certain point of saturation of durable consumer goods. Insurable properties, therefore, would be a factor that shows the vulnerability of cognizant entities, as such properties may consist of fundamentals necessary for their living. Cognizant entities with properties will create the "want" to protect them. This want will be directly related to demand for natural disaster insurance, if any.

\subsection{Want and the decision making}

If cognizant entities perceive the need to protect their properties, this want may turn to demand for protective arrangements. Natural disaster insurance is one of the arrangements. However, since premium is determined actuarially, the premium rate may thwart this latent demand, for the basic elements to consider in insurance costs are loss frequency and loss severity. These two elements are related to disaster-prone areas and 
the types of perils of natural disasters. According to these elements, insurers may demand a relatively high rate of premium coverage. Then, cognizant entities will have to consider alternatives to protect their properties with a cost/benefit (effectiveness) approach in their decision making process. If the want for insurance is strong, comparing to premium, they will decide to buy such coverage.

\section{Cognizant entity and insurance awareness}

Though it might be dangerous to simplify the historical developments concerning the relationship between a cognizant entity and insurance awareness, the following offers a brief outline of the establishment of natural disaster insurance coverages in Japan.

The cognizant entity refered to is at the general public level, for only they can create the aggregate demand for natural disaster insurance.

\subsection{Pre-introduction stage of insurance}

In a semi-feudal society, cognizant entities had generally internalized value premises that one's present life was a reflection of a previous life from the point of view of the transmigration of souls in Buddhism. From this cognizant entities understood natural disasters as punishment for wrong-doing in a previous life and accepted them totally as punishment from Heaven, particularly in cases of earthquake disasters.

As to flood disasters, cognizant entities in specific areas, from past experiences, built dikes to protect themselves from flooding. Or, they avoided flood-prone areas for settlement. We could say, then, that different types of natural disasters had different connotations in their minds. In every case, the feudal government would grant financial aid to the distraught and there were strong indications that ordinary people implicitly expected such aid or grants when confronted by disasters.

\subsection{Introduction of insurance}

The Restoration of Meiji, the epoch, destroyed a feudal system and pushed a traditional society into the modern world. The marine cargo insurance business started in 1879,12 years after the Restoration, as a commercial line. After two years, life business was introduced. In 1887, the first fire insurance company was established. The average citizen, however, did not recognize insurance as a means to protect his assets and family's livelihood.

It would take time before the average individual would become a policy holder. The period after the Restoration could be divided into several stages but three stages are chosen to develop the relationship between a cognizant entity and insurance.

a) Stage before 1945

A legacy of the Edo-period (before the Restoration of Meiji) was the attitude held regarding natural disasters in the mind of the cognizant entity. The masses did not enjoy freedom to change jobs and residence in the modern sense, and did not own much requiring protection. Cognizant entities at the average level, therefore, felt little necessity to protect their assets and/or living conditions by their own financial means. It could well be said 
that amongst the general public at that time an objective approach to insurance did not yet exist. They had resigned themselves to disasters, rationalizing them with traditional internalized value premises, for even the ruling classes did not recognize the eminently beneficial suggestions such as found in Dr. Paul Meyet's "Compulsory Household Insurance Plan " which was drafted in $1880 .{ }^{2}$

After the Great Kanto Earthquake in 1923, earthquake insurance became a social concern but private non-life insurance companies opposed a plan which required compulsory attachment to private fire insurance in 1933. This plan, therefore, was pigeonholed.

b) Stage from 1945 to $1960 \mathrm{~s}$

The surrender in 1945 lead to a more democratic way of life for the Japanese people under the U.S. occupation. This event certainly cut a number of traditional ties with some troubles remaining during the first attempts at adaptation to a new system.

Natural disasters, however, did not change their influence over the people. After the Fukui Earthquake in 1948, the Ministry of Finance prepared a draft for earthquake insurance but this did not come to pass owing to budgetary reasons. At this stage, the living situation of the masses was very poor and they were forced to work hard to live. There might not be enough demand for such insurance to be realized without governmental budgetary assistance.

As time passed, economic development made possible the aquisition of personal property by the individual on a scale never before seen. This prompted private insurers to provide several coverages for personal properties to meet demands of the masses, extending the general understanding of insurance concepts (see Table 1.)

Table 1: Ratio of the number of fire insurance policies to the number of households (from 1955 to 1962)

\begin{tabular}{lcccccccc}
\hline Year & 1955 & 1956 & 1957 & 1958 & 1959 & 1960 & 1961 & 1962 \\
Ratio & $36.4 \%$ & $42.2 \%$ & $44.2 \%$ & $48.9 \%$ & $51.6 \%$ & $51.1 \%$ & $52.4 \%$ & $54.1 \%$ \\
\hline
\end{tabular}

Source : Fact Book, The Marine and Fire Insurance Association of Japan.

c) Stage after $1960 \mathrm{~s}$

With the high growth of the Japanese economy in the late 1960s, the market for durable consumer goods was generally saturated and the masses sought land to build homes (see Tables 2 and 3). Developers themselves tried to exploit land for building houses and apartments, though this might be related to man-made hazards.

${ }^{2}$ Dr. Paul Meyet proposed a government administered fire insurance plan in 1878 , for a number of major fires occurred in Japan. In his plan, several natural disaster perils would be covered, such as earthquake, windstorm and flood. 
Table 2 : Consumption expenditure of households by type of goods and services (thousand million Yen)

\begin{tabular}{|c|c|c|c|c|}
\hline Year & Durable & Non-durable ${ }^{a}$ & Services & $\begin{array}{c}\text { Households } \\
\text { consumption }\end{array}$ \\
\hline 1965 & $1,031.3$ & $11,547.2$ & $5,637.3$ & $18,215.8$ \\
\hline 1966 & $1,258.1$ & $13,091.1$ & $6,437.8$ & $20,787.0$ \\
\hline 1967 & $1,505.0$ & $14,804.0$ & $7,518.0$ & $23,827.0$ \\
\hline 1968 & $1,942.0$ & $16,698.8$ & $8,773.5$ & $27,414.3$ \\
\hline 1969 & $2,439.2$ & $19,088.1$ & $10,158.0$ & $31,685.3$ \\
\hline 1970 & $2,772.6$ & $21,853.2$ & $11,866.9$ & $36,492.7$ \\
\hline 1971 & $3,321.9$ & $24,305.8$ & $13,669.0$ & $41,296.7$ \\
\hline 1972 & $3,683.0$ & $27,964.3$ & $16,069.2$ & $47,716.5$ \\
\hline 1973 & $4,393.1$ & $34,032.5$ & $19,231.1$ & $57,656.7$ \\
\hline 1974 & $4,809.1$ & $42,987.3$ & $23,643.7$ & $71,440.1$ \\
\hline 1975 & $5,281.5$ & $49,699.1$ & $27,750.3$ & $82,730.9$ \\
\hline 1976 & $5,577.7$ & $55,473.7$ & $32,417.2$ & $93,468.6$ \\
\hline
\end{tabular}

Source : Annual Reports on National Income, Economic Planning Agency, Government of Japan.

${ }^{a}$ Non-durable goods include semi-durable goods.

Table 3 : Number of construction for dwellings (past-war periods)

\begin{tabular}{lcccc}
\hline Year & 1945 to 1950 & 1951 to 1955 & 1956 to 1960 & 1961 to 1965 \\
\hline $\begin{array}{l}\text { No. } \\
(1,000)\end{array}$ & 2,769 & 1,562 & 2,579 & 3,996 \\
Year & 1966 to 1970 & 1971 to 1975 & 1976 to 1980 & \\
\hline $\begin{array}{l}\text { No. } \\
(1,000)\end{array}$ & 6,741 & 8,020 & 7,261 & \\
\hline
\end{tabular}

Source : White Paper of Construction, Ministry of Construction (1981).

After the Niigata Earthquake in 1964, not only government but non-life insurance association came together to discuss the realization of earthquake insurance intently with project teams to meet public demand. And at last it materialized in 1966 (referred to later).

This process shows that only demand for natural disaster insurance can not bring it into existence. It is necessary to urge government and the insurance world to recognize the needs of the masses and make efforts to establish insurance plans in order to make insurable what once were uninsurable perils. 


\section{Types of natural disaster insurance}

There are four types of coverages of natural disaster insurance to meet the demand of the general public as : 1) independent insurance ; 2) covered perils in comprehensive insurance ; 3) endorsement or rider attached to main or basic policies ; and 4) specific insurance combined with basic policies. Each type could naturally meet the demands for coverages. Following is the natural disaster coverages which private insurers have provided in the Japanese insurance marketplace.

\subsection{Private independent insurance}

In 1938 Windstorm and Flood Insurance (WFI) was planned and marketed, in which both windstorm and flood were not separated but covered together. In practice, this WFI has not been actively sold in the personal insurance market owing to high premium and is seldom purchased at the present stage. High rates of premium should be the result of a propensity of damages in flood-prone areas but could suffocate demand for coverages of natural disaster.

Private insurers tend to avoid adverse selection and their underwriting practice should, as a matter of fact, be rigidly searching. Therefore, they limit sales of WFI even in the commercial line market.

This shows the difficulty of contructing natural disaster insurance as independent insurance sold by private insurers.

\subsection{Covered perils in comprehensive insurance}

There are several types of fire insurance which cover windstorm, flood, and snow perils (not earthquake peril) damaging houses and personal properties, such as Comprehensive Householders' Policy (CHP) (having sold since 1960), Combined Shop Insurance (since 1962), Long-term Policy with Maturity Repayment (since 1968) and others. According to their Conditions, windstorm damages are limited to those caused by typhoons, cyclone and rainstorm; water damages caused by flooding and tidal wave ; snow damages caused by heavy snowfall and snowslide. In case of water damage, surface water, overflow of streams or other bodies of water are categorized under flooding.

As to the claims payment, if we refer to CHP, the following formula prescribes the amount of payment, if the damages caused by windstorm, flood and snow perils exceed $30 \%$ of insured value (since July of 1981 ):

$$
\begin{aligned}
& \text { amount insured } \times \frac{\text { amount of loss }}{\text { insured value }} \times 50 \%{ }^{a} \\
& \text { (a } 50 \%: \text { rate of reduced payment) }
\end{aligned}
$$

CHP, however, has upper limits of payments: $¥ 10,000,000$ for buildings; $¥ 5,000,000$ for personal properties. Damages by inundation above floor level are paid up to $¥ 1,000,000$ or $5 \%$ of the principal sum, whichever is less.

The fundamental reason why there are limits of payments is that natural disasters potentially bring tremendous losses to homeowners but premium factor of $\mathrm{CHP}$ will not meet such losses. 


\subsection{Endorsement or rider attached to a main policy}

In commercial line fields, the earthquake covering clause and the windstorm and flood covering clause can be attached to basic policies of fire insurance. This practice to cover earthquake peril started as extended coverage endorsement of fire insurance only in commercial lines in 1957. There was no earthquake coverage in personal line fields, however, because private insurers did not wish to take such risks, on the pretext of uninsurability of earthquake peril which can cause catastrophic loss, the unpredictable nature of its occurrence and possible occurrence at specific earthquake-prone areas.

\subsection{Specific insurance combined with basic policies}

In July, 1964, a big earthquake struck Niigata prefecture in north-western Japan, which turned out to be the momentum creating public demand for earthquake insurance, as fire caused by earthquake was excluded by the Fire Insurance General Conditions (even by the CHP General Conditions). The Japanese government, meeting the keen demand of the general public for the necessity of earthquake insurance, passed the Law concerning Earthquake Insurance in 1966, after numerous studies conducted within the non-life insurance industry. Then, with the passing of the Law concerning Earthquake Reinsurance, the Japan Earthquake Reinsurance Co. Ltd. was established in 1966.

Earthquake insurance thus established is attached to the CHP and other personal lines of fire insurance, though often taken to be independent insurance, its efficacy derives from the main policy. If people do not refuse this earthquake insurance, coverages for dwellings and/or personal properties are automatically issued with special rates of earthquake insurance. Premium rates of this earthquake insurance are shown in Table 4 . These rates are based on statistics of occurrence over 467 years in Japan.

Table 4 : Earthquake insurance premium rates

\begin{tabular}{llccccc}
\hline Class & & 1 & 2 & 3 & 4 & 5 \\
\hline & Dwellings & 2.30 & 2.90 & 3.70 & 4.20 & 4.80 \\
$\begin{array}{l}\text { Wooden Construction } \\
\text { (Inferior) }\end{array}$ & $\begin{array}{l}\text { Personal } \\
\text { Property }\end{array}$ & 1.70 & 2.00 & 2.60 & 3.00 & 3.40 \\
\hline & Dwellings & .70 & .80 & 1.40 & 1.60 & 1.80 \\
$\begin{array}{l}\text { Non-Wooden Construction } \\
\text { (Superior) }\end{array}$ & $\begin{array}{l}\text { Personal } \\
\text { Property }\end{array}$ & .50 & .60 & 1.00 & 1.10 & 1.30 \\
\hline
\end{tabular}

(As of January, 1983)

The sum insured of this insurance has the range of $30 \%$ to $50 \%$ of that of the basic policy (e.g. such as CHP) with uniform limits of $¥ 10,000,000$ for any one building and of $¥ 5,000,000$ for household goods (personal properties) contained in any one building. The limitation of the sum insured prevents the accumulation of huge earthquake exposures and avoids difficulties in claims settlement. 
Prior to July of 1980 , only total loss of dwelling was the condition of payment of claims. After revision of Earthquake Insurance in July, 1980, claims payable have extended to cases of $50 \%$ or more loss of dwelling. Claims payable for household goods are under similar condition to the dwelling containing them. This revision is due to the dissatisfaction raised by the general public about the validity of Earthquake Insurance, as its condition of claims payment was limited only to the total loss of a dwelling, when the Miyagioki Earthquake occurred in June, 1978.

(This Earthquake Insurance has a reinsurance arrangement with the government under the Law concerning Earthquake Reinsurance.)

\section{Summary}

Modernization surely made cognizant entities independent. Industrialization made possession of property possible for them, which established the fundamentals for modern living and necessitated protection, if disaster occurs. Cognizant entities take into consideration the cost/benefit approach to get necessary protection. Insurance premium should be one of the important factors. If the premium is high enough to cover estimated losses of a natural disaster, coverage provided may be beyond their " want " and demand shrinks. Some governmental measures, therefore, will be necessarily invited to reduce premium to the point where they will buy.

The approach we adopted here is that cognizant entities, with properties needed for daily life, will provoke demand for natural disaster insurance in developmental stages. 